Cochrane Database of Systematic Reviews

\title{
Antibiotics for persistent cough or wheeze following acute bronchiolitis in children (Review)
}

McCallum GB, Plumb EJ, Morris PS, Chang AB

McCallum GB, Plumb EJ, Morris PS, Chang AB.

Antibiotics for persistent cough or wheeze following acute bronchiolitis in children.

Cochrane Database of Systematic Reviews 2017, Issue 8. Art. No.: CD009834.

DOI: 10.1002/14651858.CD009834.pub3.

www.cochranelibrary.com 
TABLE OF CONTENTS

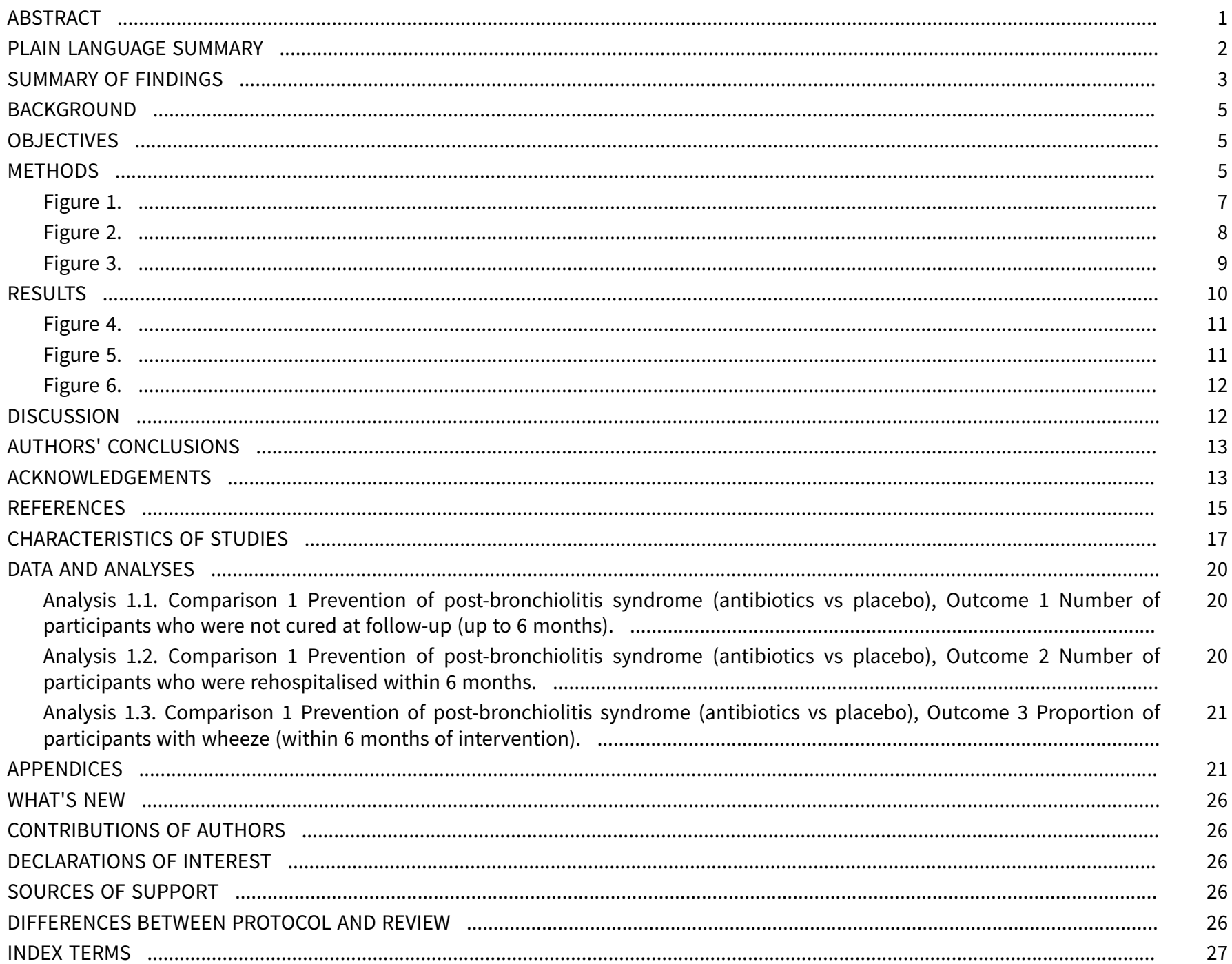


[Intervention Review]

\section{Antibiotics for persistent cough or wheeze following acute bronchiolitis in children}

Gabrielle B McCallum ${ }^{1}$, Erin J Plumb¹, Peter S Morris ${ }^{1}$ Anne B Chang 1

${ }^{1}$ Child Health Division, Menzies School of Health Research, Charles Darwin University, Darwin, Australia

Contact: Gabrielle B McCallum, Child Health Division, Menzies School of Health Research, Charles Darwin University, Darwin, Northern Territory, 0810, Australia.gabrielle.mccallum@menzies.edu.au.

Editorial group: Cochrane Airways Group.

Publication status and date: New search for studies and content updated (no change to conclusions), published in Issue 8, 2017.

Citation: McCallum GB, Plumb EJ, Morris PS, Chang AB. Antibiotics for persistent cough or wheeze following acute bronchiolitis in children. Cochrane Database of Systematic Reviews 2017, Issue 8. Art. No.: CD009834. DOI: 10.1002/14651858.CD009834.pub3.

Copyright ( 2017 The Cochrane Collaboration. Published by John Wiley \& Sons, Ltd.

\section{A B S T R A C T}

\section{Background}

Bronchiolitis is a common acute respiratory condition with high prevalence worldwide. This clinically diagnosed syndrome is manifested by tachypnoea (rapid breathing), with crackles or wheeze in young children. In the acute phase of bronchiolitis ( $\leq 14$ days), antibiotics are not routinely prescribed unless the illness is severe or a secondary bacterial infection is suspected. Although bronchiolitis is usually selflimiting, some young children continue to have protracted symptoms (e.g. cough and wheezing) beyond the acute phase and often represent to secondary care.

\section{Objectives}

To compare the effectiveness of antibiotics versus controls (placebo or no treatment) for reducing or treating persistent respiratory symptoms following acute bronchiolitis within six months of acute illness.

\section{Search methods}

We searched the following databases: the Cochrane Airways Group Register of Trials, the Cochrane Central Register of Controlled Trials (CENTRAL), MEDLINE (Ovid), Embase (Ovid), the World Health Organization (WHO) trial portal, the Australian and New Zealand Clinical Trials Registry, and ClinicalTrials.gov, up to 26 August 2016.

\section{Selection criteria}

We included randomised controlled trials (RCTs) comparing antibiotics versus controls (placebo or no treatment) given in the post-acute phase of bronchiolitis (> 14 days) for children younger than two years with a diagnosis of bronchiolitis.

\section{Data collection and analysis}

Two review authors independently assessed studies against predefined criteria, and selected, extracted, and assessed data for inclusion. We contacted trial authors for further information.

\section{Main results}

In this review update, we added one study with 219 children. A total of two RCTs with 249 children ( $n=240$ completed) were eligible for inclusion in this review. Both studies contributed to our primary and secondary outcomes, but we assessed the quality of evidence for our three primary outcomes as low, owing to the small numbers of studies and participants; and high attrition in one of the studies. Data show no significant differences between treatment groups for our primary outcomes: proportion of children $(n=249)$ who had persistent symptoms at follow-up (odds ratio (OR) $0.69,95 \%$ confidence interval ( $\mathrm{Cl}) 0.37$ to 1.28; fixed-effect model); and number of children (n $=240$ ) rehospitalised with respiratory illness within six months (OR $0.54,95 \% \mathrm{Cl} 0.05$ to 6.21 ; random-effects model). We were unable 
to analyse exacerbation rate because studies used different methods to report this information. Data showed no significant differences between treatment groups for our secondary outcome: proportion of children $(n=240)$ with wheeze at six months $($ OR $0.47,95 \% \mathrm{Cl} 0.06$ to 3.95; random-effects model). One study reported bacterial resistance, but only at 48 hours (thus with limited applicability for this review). Another study reported adverse events from which all children recovered and remained in the study.

\section{Authors' conclusions}

Current evidence is insufficient to inform whether antibiotics should be used to treat or prevent persistent respiratory symptoms in the post-acute bronchiolitis phase. Future RCTs are needed to evaluate the efficacy of antibiotics for reducing persistent respiratory symptoms. This is particularly important in populations with high acute and post-acute bronchiolitis morbidity (e.g. indigenous populations in Australia, New Zealand, and the USA).

\section{PLAIN LANGUAGE SUMMARY}

\section{Antibiotics for persistent cough or wheeze following acute bronchiolitis in children}

\section{Review question}

How do antibiotics compare with placebo or no treatment for reducing or treating persistent respiratory symptoms in children following acute bronchiolitis?

\section{Background}

Bronchiolitis is a lung condition that commonly affects children across the world. Young children with bronchiolitis normally have a cough, fast and difficult breathing, and poor feeding. Antibiotics are not usually prescribed unless the illness is severe, or a secondary bacterial infection is suspected. However, some children continue to have ongoing problems (i.e. wheeze, cough) after the acute infection (> 14 days), increasing the risk of ongoing burden of disease and costs to the health system. These children often re-present for further medical care in the community (general practitioners and health providers) or in hospital (emergency departments). Antibiotics used to treat these ongoing symptoms may get rid of bacteria in the lungs and may improve long-term outcomes.

\section{Study characteristics}

This review update (up to 26 August 2016) includes two clinical trials that compared antibiotics with placebo for children in the post-acute bronchiolitis phase (> 14 days). The first was reported from Turkey and enrolled 30 infants aged seven months or younger. The second was reported from Australia and New Zealand and enrolled 249 infants aged 24 months or younger. Both trials initiated treatment during hospitalisation for bronchiolitis and provided follow-up for six months post hospitalisation.

\section{Key results}

This review update includes a total of two trials with 249 children $(n=240$ completed). Both studies contributed to primary and secondary outcomes, but the quality of evidence was low. Review authors noted no significant differences between treatment groups for our primary outcomes: proportion of children $(n=249)$ who had persistent symptoms at follow-up, and number of children $(n=240)$ rehospitalised with respiratory illness within six months; nor for our secondary outcome: proportion of children $(n=240)$ with wheeze at six months. One study reported bacterial resistance, but only at 48 hours. One study reported adverse events from which all children recovered and remained in the study.

\section{Quality of evidence}

Currently, not enough evidence is available to inform whether antibiotics should be used to treat or prevent persistent respiratory symptoms in the post-acute phase of bronchiolitis. Clinical trials are needed to evaluate the efficacy of antibiotics for reducing persistent respiratory symptoms, especially in countries where morbidity of bronchiolitis is high (e.g. indigenous populations). 
SUMMARY OF FINDINGS

Summary of findings for the main comparison. Antibiotics compared with placebo or no treatment for persistent respiratory symptoms following acute bronchiolitis

Antibiotics compared with placebo or no treatment for persistent respiratory symptoms following acute bronchiolitis

Patient or population: children $<24$ months with persistent respiratory symptoms following acute bronchiolitis

Setting: post-acute bronchiolitis phase $>14$ days

Intervention: antibiotics^

Comparison: placebo or no treatment^

\begin{tabular}{|c|c|c|c|c|c|c|}
\hline \multirow[t]{2}{*}{ Outcomes } & \multicolumn{2}{|c|}{ Anticipated absolute effects* $(95 \% \mathrm{CI})$} & \multirow{2}{*}{$\begin{array}{l}\text { Relative effect } \\
(95 \% \mathrm{Cl})\end{array}$} & \multirow{2}{*}{$\begin{array}{l}\text { No. of partici- } \\
\text { pants } \\
\text { (studies) }\end{array}$} & \multirow{2}{*}{$\begin{array}{l}\text { Quality of the } \\
\text { evidence } \\
\text { (GRADE) }\end{array}$} & \multirow[t]{2}{*}{ Comments } \\
\hline & $\begin{array}{l}\text { Risk with } \\
\text { placebo }\end{array}$ & Risk with antibiotics & & & & \\
\hline $\begin{array}{l}\text { Number of participants who were not cured at } \\
\text { follow-up } \\
\text { Follow-up: } 6 \text { months }\end{array}$ & 234 per 1000 & $\begin{array}{l}174 \text { per } 1000 \\
\text { (102 to } 282)\end{array}$ & $\begin{array}{l}\text { OR } \mathbf{0 . 6 9} \\
\text { (0.37 to } 1.28)\end{array}$ & $\begin{array}{l}249 \\
\text { (2 RCTs) }\end{array}$ & $\begin{array}{l}\oplus \oplus \odot \odot \\
\mathrm{LOW} a\end{array}$ & \\
\hline $\begin{array}{l}\text { Proportion of participants with recurrent } \\
\text { wheeze } \\
\text { Follow-up: } 6 \text { months }\end{array}$ & 123 per 1000 & $\begin{array}{l}99 \text { per } 1000 \\
(47 \text { to } 195)\end{array}$ & $\begin{array}{l}\text { OR } 0.47 \\
(0.06 \text { to } 3.95)\end{array}$ & $\begin{array}{l}240 \\
\text { (2 RCTs) }\end{array}$ & $\begin{array}{l}\oplus \oplus \oplus \ominus \\
\text { LOWa }\end{array}$ & \\
\hline
\end{tabular}

^Intervention/Comparison group: treatment initiated during child's hospitalisation for acute bronchiolitis

*The risk in the intervention group (and its $95 \%$ confidence interval) is based on assumed risk in the comparison group and the relative effect of the intervention (and its $95 \% \mathrm{Cl}$ )

$\mathrm{Cl}$ : confidence interval; OR: odds ratio

We used GRADEPro software to create this table ( GRADEpro GDT 2015)

\section{GRADE Working Group grades of evidence}

High quality: We are very confident that the true effect lies close to that of the estimate of the effect

Moderate quality: We are moderately confident in the effect estimate: The true effect is likely to be close to the estimate of the effect, but there is a possibility that it is substantially different

Low quality: Our confidence in the effect estimate is limited: The true effect may be substantially different from the estimate of the effect

Very low quality: We have very little confidence in the effect estimate: The true effect is likely to be substantially different from the estimate of effect 


\section{B A C K G R O U N D}

\section{Description of the condition}

Bronchiolitis is a common acute respiratory condition, with a high prevalence worldwide (Chang 2009). This clinically diagnosed syndrome is manifested by tachypnoea (rapid breathing) with crackles or wheeze in very young children (Ralston 2014). Multiple viruses and some atypical bacteria can cause bronchiolitis, including respiratory syncytial virus (RSV), influenza, human metapneumovirus, rhinovirus, influenza, parainfluenza, adenovirus, and mycoplasma.

In the acute phase ( $\leq 14$ days) of bronchiolitis, antibiotics are usually only recommended if the illness is severe, or if a secondary bacterial infection is suspected (Ralston 2014; NICE 2015). However, a Cochrane review found "minimal evidence to support the use of antibiotics for acute bronchiolitis" (Spurling 2011).

Although bronchiolitis is typically self-limiting, lasting from three to seven days, a number of children continue to display respiratory symptoms beyond the acute phase. Swingler 2000 reported that $39 \%$ of infants were still symptomatic after 14 days, $18 \%$ after 21 days, and $9 \%$ after 28 days. Other studies have shown that $40 \%$ to $50 \%$ of those hospitalised have a "grumbling, sometimes protracted, respiratory syndrome of persistent cough and recurrent viral-induced wheeze" (SIGN 2006). Although symptoms such as cough and wheezing may be mild in post-acute bronchiolitis, they have the potential to increase the burden of disease (e.g. presenting or re-presenting to secondary care). Furthermore, among some populations (e.g. indigenous children) (Bailey 2009), recurrent hospitalisations are common, and prolonged symptoms (e.g. wet cough) have been associated with a future diagnosis of bronchiectasis (McCallum 2016). Cohort studies have also suggested that bronchiolitis may trigger, or may be associated with future development of asthma (Sigurs 2000; Carroll 2009).

The possible biological mechanism that may give rise to persistent respiratory symptoms is likely to be multi-factorial. In bronchiolitis, airway oedema occurs, the airway epithelium is affected, and cilial damage can persist for 13 to 17 weeks (Wong 2005). Cilia are an important component of the airway's clearance mechanism. Damage to airway cilia and possible impairment of innate immunity in severe bronchiolitis (Halfhide 2008) predispose these infants to secondary bacterial infection. Persistent or delayed resolution of airway oedema or the presence of secondary bacterial infection in the airways (endobronchial infection) related to persistent cilial damage can cause wheeze, cough, or both.

\section{Description of the intervention}

In the presence of endobronchial infection, antibiotics are a potentially beneficial intervention for individuals with post-acute bronchiolitis. When given early (i.e. before the onset of secondary bacterial infection), antibiotics have the potential to prevent persistent symptoms; when given later (i.e. after the acute episode), they are used to treat the bacterial endobronchial infection. Antibiotics may be given orally, intravenously, or via a nebuliser. The efficacy of antibiotics given in the acute or non-acute phase may be influenced by study setting. For example, in non-affluent settings, where dense bacterial colonisation of the nasopharynx is higher than in affluent urban settings (Leach 1994), antibiotics may be more effective.

\section{How the intervention might work}

Antibiotics may be useful for treating individuals with symptoms of post-acute bronchiolitis by preventing or eliminating secondary bacterial infection in the lower airways. Lower airway bacterial infection following viral respiratory infection has been well described in airway cells in vitro (Didierlaurent 2008), as well as in epidemiological and clinical studies (McCullers 2006). In addition to antibacterial effects, antibiotics such as macrolides, through their anti-inflammatory properties, may confer immunomodulatory effects, thus influencing neutrophilic inflammation (GiamarellosBourboulis 2008; Zarogoulisidis 2011) and reducing airway oedema. Elimination of endobronchial infection or inflammation, or both, may reduce airway secretions or oedema, or both, consequently improving persistent respiratory symptoms.

\section{Why it is important to do this review}

A small but significant number of children with acute bronchiolitis have persistent problems beyond the acute infection (for a variety of reasons). These children are usually referred to secondary and tertiary practices (i.e. outside of general practice) and are treated with a variety of medications such as antibiotics, bronchodilators, inhaled (Fox 1999) and oral corticosteroids (Blom-Danielle 2007), and leukotriene receptor antagonists (Kim 2010). This clinical issue has been identified as an area that needs more research (Su 2014). Further, use of any medication may result in adverse events, and persistent symptoms may affect the burden of disease and health economics. Thus, a systematic review of the benefits and other effects achieved by using antibiotics in the post-acute bronchiolitis phase should prove useful in guiding clinical practice.

\section{O B JECTIVES}

To compare the effectiveness of antibiotics versus controls (placebo or no treatment) for reducing or treating persistent respiratory symptoms following acute bronchiolitis within six months of acute illness.

\section{METHO DS}

\section{Criteria for considering studies for this review}

\section{Types of studies}

We planned to include randomised controlled trials (RCTs) comparing antibiotics versus controls (placebo or no treatment) given during the post-acute phase of bronchiolitis (> 14 days). Antibiotics could have been started during the acute phase (at the start of illness to prevent post-bronchiolitis symptoms) or during the post-acute phase (for treatment of post-bronchiolitis symptoms).

\section{Types of participants}

Included were previously healthy children (aged two years or younger) with bronchiolitis (as defined by study authors) who were treated with antibiotics beyond the acute bronchiolitis period ( $>14$ days).

Excluded were children with any underlying chronic disease such as lung disease (e.g. cystic fibrosis, bronchopulmonary dysplasia, bronchiectasis, aspiration), cardiac disease, or immunodeficiency (primary or secondary). 


\section{Types of interventions}

We planned to examine all types of antibiotics given beyond the acute period ( $>14$ days), including those prescribed for acute bronchiolitis that lasted beyond the acute phase of 14 days.

\section{Types of outcome measures}

\section{Primary outcomes}

- Number of participants who were not cured at follow-up (up to six months) (i.e. wheeze/cough)

- Exacerbation rate (up to six months)

- Number of participants rehospitalised for a respiratory illness within six months of onset of illness

\section{Secondary outcomes}

- Mean difference in cough indices (e.g. cough diary, frequency, or scores; quality of life)

- Mean difference in wheeze indices (e.g. cough diary, frequency, or scores; quality of life)

- Proportion of participants with wheeze (within six months of intervention)

- Adverse events (e.g. proportion of participants requiring new medications or developing pneumonia)

- Bacterial resistance

We selected complete resolution of symptoms as the primary outcome, as previously healthy children should completely recover after an episode of acute bronchiolitis. Cohort studies of bronchiolitis (Bailey 2009) have reported pneumonia and recurrent wheeze (some cases requiring repeat hospitalisation). Thus, we considered re-admission for a respiratory infection and recurrent wheeze as important outcomes.

\section{Search methods for identification of studies}

\section{Electronic searches}

The Trial Search Co-ordinator for the Cochrane Airways Group performed the search, identifying trials through the following databases.

- Cochrane Airways Group Register of Trials (all years).

- Cochrane Central Register of Controlled Trials (CENTRAL; 2016, Issue 8).
- MEDLINE (Ovid) September week 42012 to August week 32016.

- Embase (Ovid) week 122012 to week 342016.

- ClinicalTrials.gov.

- World Health Organization (WHO) trials portal.

- Australian and New Zealand Clinical Trials Registry.

We have listed the search strategies in Appendix 1. We searched all databases from their inception to the present and imposed no restriction on language of publication.

The Cochrane Airways Group (Elizabeth Stovold) performed the search on 26 August 2016.

\section{Searching other resources}

We checked the reference lists of included studies and of relevant review articles for additional references. We contacted authors of identified trials, when appropriate, to ask about other published and unpublished studies.

\section{Data collection and analysis}

\section{Selection of studies}

Using article titles, abstracts, or descriptors, two review authors (GBM and $A B C$ in the original review; GBM and EJP for the search from 2012 to 2016) independently reviewed literature searches to identify potentially relevant trials for full review. They conducted searches of bibliographies and texts and other portals to look for additional eligible studies (e.g. Clinicaltrials.gov; WHO trial registry). From the full-text articles, the two review authors independently assessed trials for inclusion on the basis of specific predefined criteria.

\section{Data extraction and management}

We had no disagreements but had planned to resolve disagreements through discussion or through consultation with another review author (PSM). We extracted data using a standardised data collection form, and entered the data into Review Manager 5.3 (RevMan 2014), in accordance with recommendations provided in the Cochrane Handbook for Systematic Reviews of Interventions (Higgins 2011). When required, we sought further information from study authors. We recorded the selection process in a PRISMA flow diagram (Figure 1). 
Figure 1. Study flow diagram.

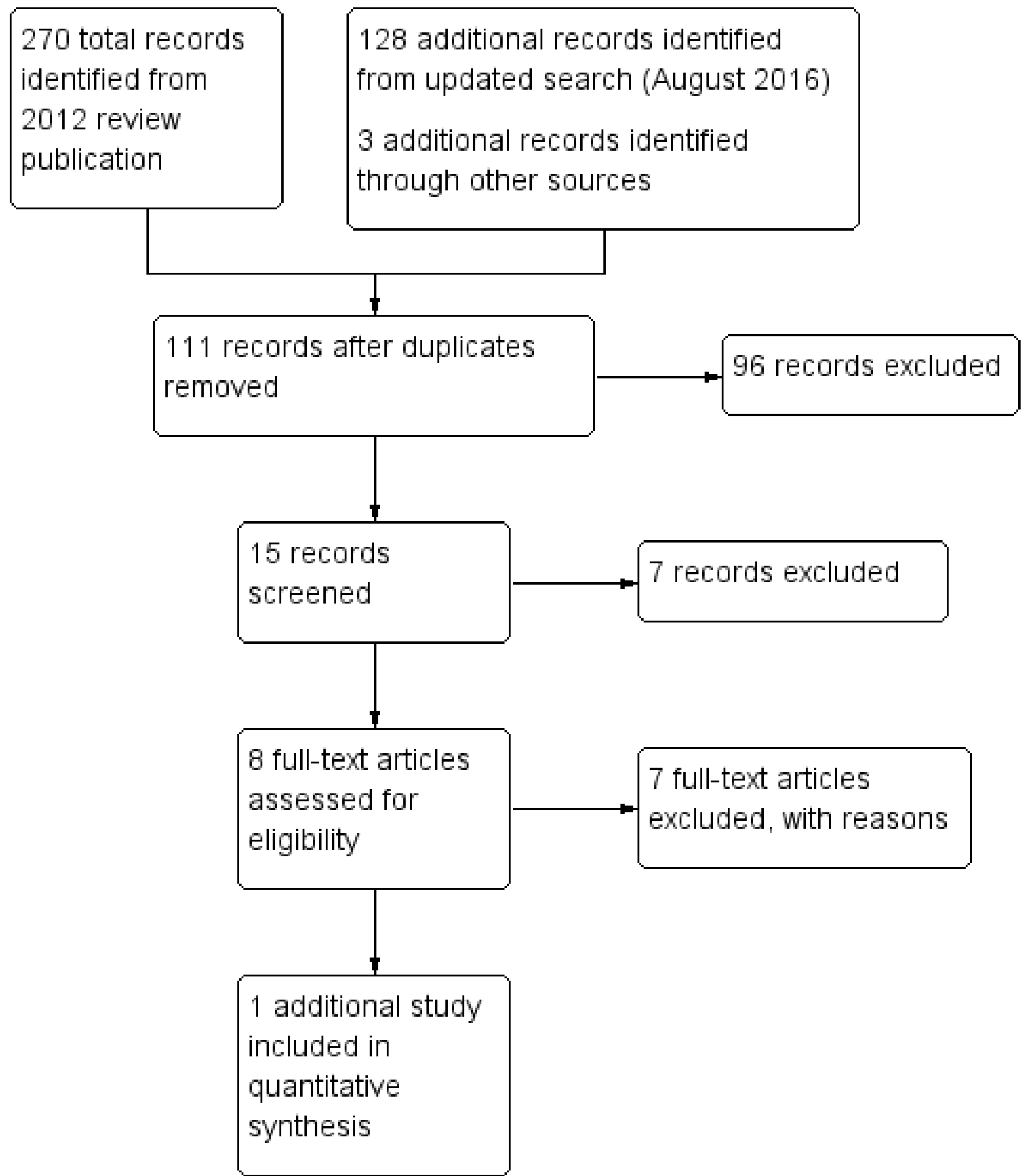

Assessment of risk of bias in included studies

Two review authors (GBM and ABC for the original search; GBM and EJP for the 2016 search) independently assessed risk of bias for each study using criteria outlined in the Cochrane Handbook for
Systematic Reviews of Interventions (Higgins 2011). We planned that we would resolve disagreements by discussion or by consultation with a third party. We assessed risk of bias according to the following domains (Figure 2). 
Figure 2. Risk of bias graph: review authors' judgements about each risk of bias item presented as percentages across all included studies.

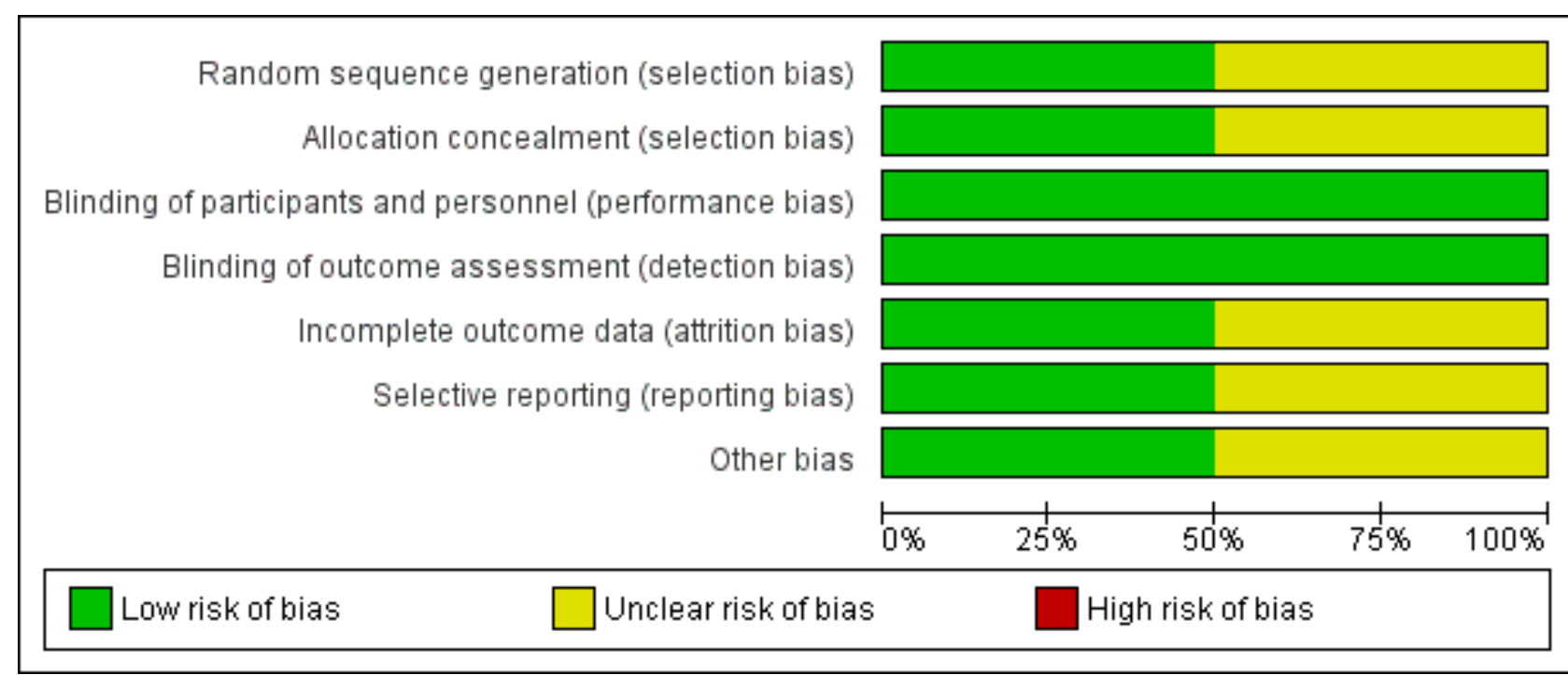

- Allocation sequence generation (selection bias).

- Concealment of allocation (selection bias).

- Blinding of participants (performance bias).

- Outcome assessment (detection bias).

- Incomplete outcome data (attrition bias).
- Selective outcome reporting (reporting bias).

- Other bias.

We graded risk for each potential source of bias as high, low, or unclear, and provided justification for our judgements in the 'Risk of bias' table (Figure 2; Figure 3). 
Figure 3. Risk of bias summary: review authors' judgements about each risk of bias item for each included trial.

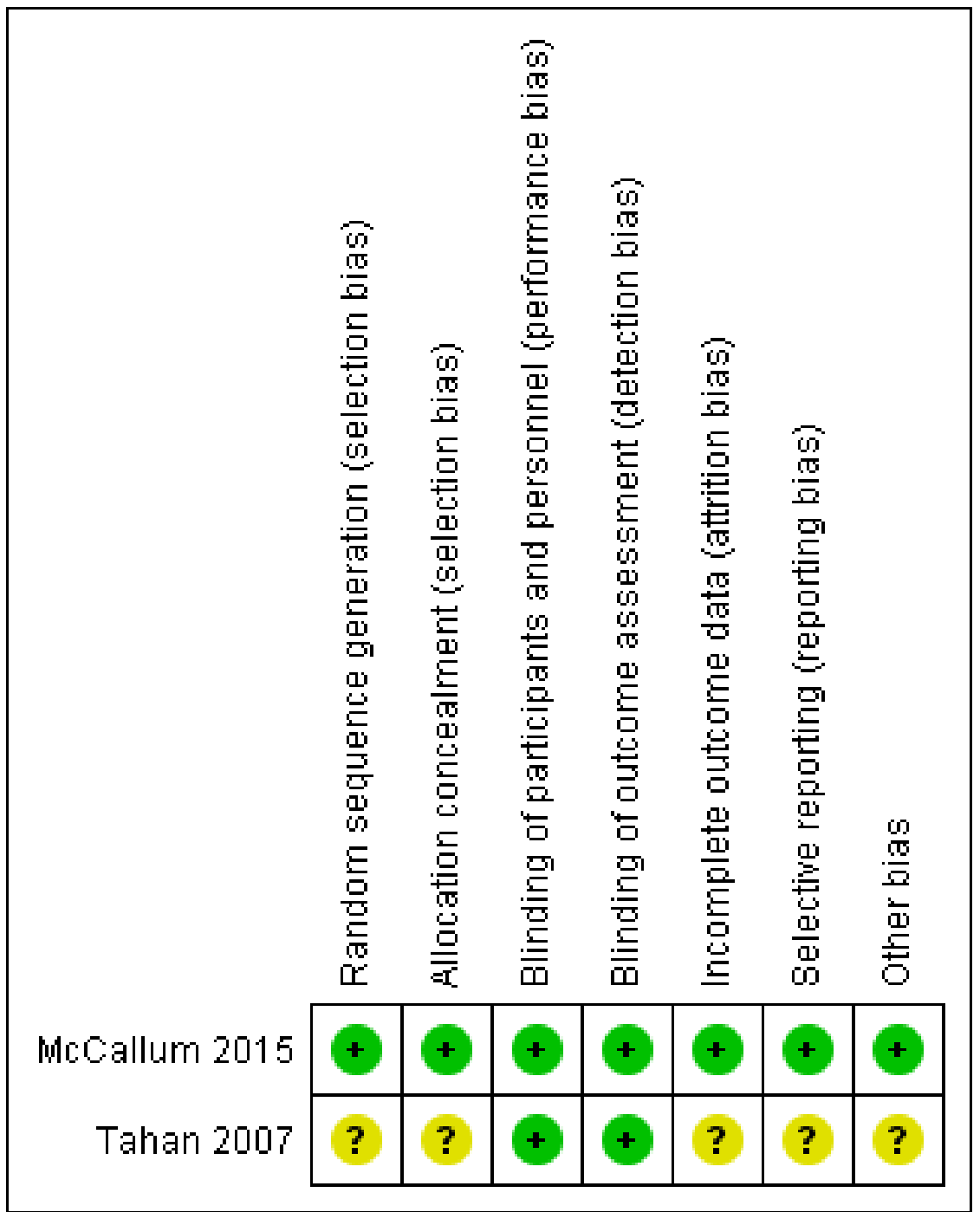

\section{Measures of treatment effect}

We analysed dichotomous data as odds ratios (ORs), and continuous data as mean differences (MDs) or standardised mean differences (SMDs) (as required). We then entered data presented as a scale with a consistent direction of effect. We undertook metaanalyses only when this was meaningful and considered differences in study populations, inclusion/exclusion criteria, interventions, outcome assessments, and estimated effect sizes.

\section{Unit of analysis issues}

For dichotomous data, we reported the proportion of participants contributing to each outcome in comparisons versus the total number randomised. Cross-over and cluster-randomised trials are not appropriate for this target population; therefore we did not include them.

\section{Dealing with missing data}

Review authors planned to contact investigators or study sponsors to verify key study characteristics and to request missing numerical outcome data when necessary. For the previous review, we attempted to contact investigators from Tahan 2007 to verify study characteristics and to obtain missing numerical outcome data; however, we were unsuccessful in making contact. One of the review authors (EJP) who was not involved in McCallum 2015 obtained additional data from study authors upon request.

\section{Assessment of heterogeneity}

We proposed that we would describe any heterogeneity between study results and would test the data using a $\mathrm{Chi}^{2}$ test to see whether heterogeneity reached statistical significance. We would include the $95 \%$ confidence interval $(\mathrm{Cl})$, estimated via a random-effects model, when we had concerns about statistical heterogeneity. We considered heterogeneity to be significant when $P$ was less than 0.10 (Higgins 2011).

\section{Assessment of reporting biases}

If reporting bias was suspected (see Selective reporting (reporting bias) in the Risk of bias in included studies table below), we planned to contact study authors to request missing outcome data. We planned that if missing data were not provided, and if this was thought to introduce serious bias, we would explore the impact of 
including such studies in the overall assessment by performing a sensitivity analysis.

\section{Data synthesis}

We created Summary of findings for the main comparison (SoF) in accordance with methods and recommendations described in Section 8.5 and Chapter 12 of the Cochrane Handbook for Systematic Reviews of Interventions (Higgins 2011), using GRADEpro software.

\section{Subgroup analysis and investigation of heterogeneity}

We planned to perform subgroup analysis based on:

- type of control arm (placebo/no treatment);

- severity of disease (hospitalised vs non-hospitalised);

- treatment with macrolides versus other types of antibiotics;

- $\operatorname{short~(~} \leq 7$ days) versus longer ( $>7$ days) courses of antibiotics;

- time of commencement of antibiotics (within $\leq 14$ days or $>14$ days of onset of bronchiolitis); and

- setting of the study (affluent vs non-affluent setting).

\section{Sensitivity analysis}

We planned to conduct sensitivity analyses to assess the impact of the following potentially important factors on overall outcomes.

- Study quality (adequate allocation concealment and blinding).

- Variation in inclusion criteria.

- Analysis via a random-effects model.

- Analysis by "treatment received."

\section{RE S U L T S}

\section{Description of studies}

See Characteristics of included studies and Characteristics of excluded studies for full details.

\section{Results of the search}

For the previous review (McCallum 2012), the Cochrane Airways Group Specialised Register (CAGR) revealed 270 potentially relevant titles (the 2012 review identified seven abstracts but included only one study (Tahan 2007)). For this update, we identified 128 additional articles through the updated search (up to August 2016), and three others from reference lists. After removing duplicates and assessing titles, we retrieved eight articles for full review, but only a single new study (McCallum 2015) fulfilled the inclusion criteria for this update (Figure 1). The seven remaining studies did not meet review inclusion criteria (Friis 1984; Kneyber 2008; Kabir 2009; Mazumder 2009; Pinto 2012; McCallum 2013; Beigelman 2015).

\section{Included studies}

We added one new study (McCallum 2015), thus including two studies in this updated review (see Characteristics of included studies). This review includes a total of 249 children who had been enrolled ( $n=240$ completed). One trial was a singlecentre study (Tahan 2007), and the other a multi-centre study (McCallum 2015). Both studies provided follow-up for six months post hospitalisation.

\section{Participants}

Included studies used different inclusion and exclusion criteria for participants. Tahan 2007 enrolled infants aged seven months or younger who had been admitted to a paediatric hospital in Turkey with RSV-confirmed bronchiolitis. Investigators randomised infants to receive oral clarithromycin $15 \mathrm{mg} / \mathrm{kg} / \mathrm{d}$ or placebo for three weeks, commencing in hospital. McCallum 2015 enrolled Indigenous infants aged 24 months or younger who had been admitted to Royal Darwin Hospital (Australia), Townsville Hospital (Australia), or Auckland Starship Children's Hospital (New Zealand) with a clinical diagnosis of bronchiolitis. Researchers randomised infants to receive azithromycin $30 \mathrm{mg} / \mathrm{kg} /$ dose or an equal volume of placebo, given weekly for three weeks commencing in hospital.

\section{Outcomes}

Both studies (Tahan 2007; McCallum 2015) reported length of stay (hospitalisation) and oxygen supplementation as their primary outcomes. Secondary outcomes varied between studies. Tahan 2007 reported wheezing episodes with parents surveyed over the phone at six months. McCallum 2015 reported wheezing of infants at the day 21 clinical review, adverse events, bacterial resistance (at 48 hours), and hospital re-admissions for respiratory illness at six months.

We have described all study characteristics in the Characteristics of included studies table.

\section{Excluded studies}

We excluded studies from the review (Friis 1984; Kneyber 2008; Kabir 2009; Mazumder 2009; Pinto 2012; McCallum 2013; Beigelman 2015) usually because interventions were provided during the acute phase (e.g. $\leq 14$ days) (see Characteristics of excluded studies).

\section{Risk of bias in included studies}

We have summarised risk of bias for included studies in Figure 2 and Figure 3.

\section{Allocation}

We assessed only McCallum 2015 as having low risk for both domains. Investigators adequately described the method of randomisation, reporting that an independent statistician who 'used a computer-generated, permuted block design' generated randomisation sequences. Tahan 2007 reported that participants were "randomised by a single study nurse" but did not clearly describe how allocation or concealment was done or maintained.

\section{Blinding}

We assessed McCallum 2015 as having low risk for both domains. Researchers in the McCallum 2015 study adequately described that the study team, which included investigators/study nurses, families, and participants, remained blinded to randomisation until the analysis had been completed. Treatment allocation was concealed in a sealed opaque envelope. We assessed Tahan 2007 as having low risk of bias. Trial authors described that participants, families, and investigators remained blinded to randomisation until the study had been completed. 


\section{Incomplete outcome data}

We assessed McCallum 2015 as having low risk of bias, as more than $90 \%$ of participants completed study follow-up. We assessed Tahan 2007 as having unclear risk. Of 30 infants enrolled, nine were excluded (three from the clarithromycin group and six from the placebo group), as they had received corticosteroid treatment in hospital (Tahan 2007). The attrition rate was high (31\%), and investigators did not report data for these children, but we remain uncertain about the impact of this bias on results of the review.

\section{Selective reporting}

We assessed Tahan 2007 as having unclear risk. It is not clear whether an intention-to-treat (ITT) analysis was performed. It also is not clear whether the trial had been registered. We assessed McCallum 2015 as having low risk. Researchers adequately described the method of analysis used (e.g. ITT analysis) and had registered the trial with the Australian and New Zealand Clinical Trials Registry (ACTRN1261000036099).

\section{Other potential sources of bias}

We identified no other potential sources of bias.

\section{Effects of interventions}

See: Summary of findings for the main comparison Antibiotics compared with placebo or no treatment for persistent respiratory symptoms following acute bronchiolitis

\section{Primary outcomes}

Number of participants who were not cured at follow-up (up to six months) (i.e. wheeze/cough)

Both studies (Tahan 2007; McCallum 2015) reported numerical data for this outcome that were based on re-admissions to hospital with wheezing six months after hospital discharge. Data showed no significant differences between treatment groups (odds ratio (OR) 0.69 ; $95 \%$ confidence interval $(\mathrm{Cl}) 0.37$ to 1.28 ; Analysis 1.1; Figure 4).

Figure 4. Forest plot of comparison: 1 Prevention of post-bronchiolitis syndrome (antibiotics vs placebo), outcome: 1.1 Number of participants who were not cured at follow-up (up to 6 months).

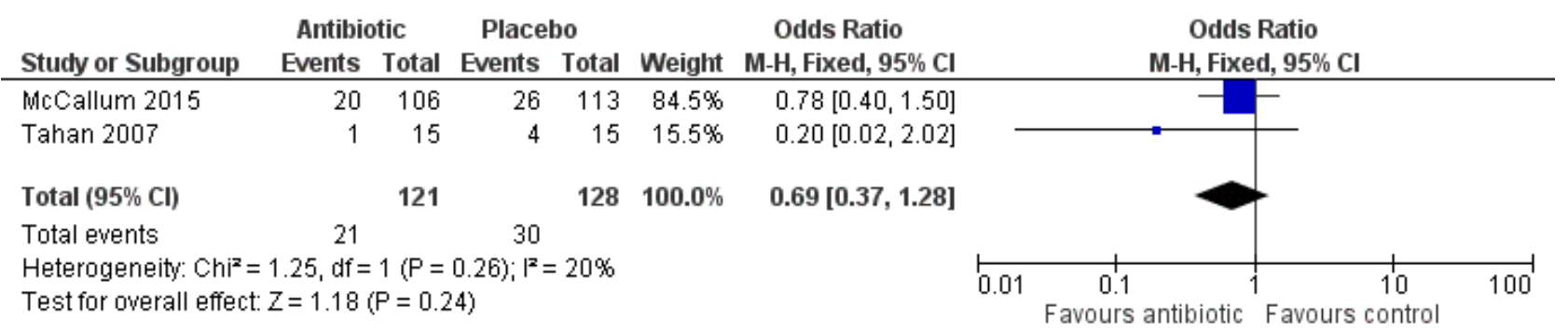

\section{Exacerbation rate (up to six months)}

Both studies (Tahan 2007; McCallum 2015) reported respiratory exacerbations up to six months after hospital discharge. Tahan 2007 conducted a phone interview with parents. Five children were rehospitalised with a wheezing illness within six months of discharge (clarithromycin group $n=1$; placebo group $n=4$ ) (Tahan 2007). McCallum 2015 conducted a medical chart review at six months and records showed 81 respiratory hospitalisations (azithromycin group $\mathrm{n}=47$; placebo group $\mathrm{n}=34$ ) among 56 participants (azithromycin group $n=31$; placebo group $n=25$ ). Of these, 60 admissions were for a wheezing-associated illness.

\section{Number of participants rehospitalised for a respiratory illness within six months of illness onset}

Both McCallum 2015 and Tahan 2007 found no significant differences between groups in numbers of participants re-admitted within six months (OR $1.19,95 \% \mathrm{Cl} 0.67$ to 2.12 ). Trial results showed statistical heterogeneity for this outcome $(12=75 \%$; $P=0.05)$, which was likely due to the small number of participants included in Tahan 2007. Random-effects analysis revealed that differences between groups remained non-significant (OR 0.54, 95\% Cl 0.05 to 6.21; Analysis 1.2; Figure 5).

Figure 5. Forest plot of comparison: 1 Prevention of post-bronchiolitis syndrome (antibiotics vs placebo), outcome: 1.2 Number of participants who were rehospitalised within 6 months.

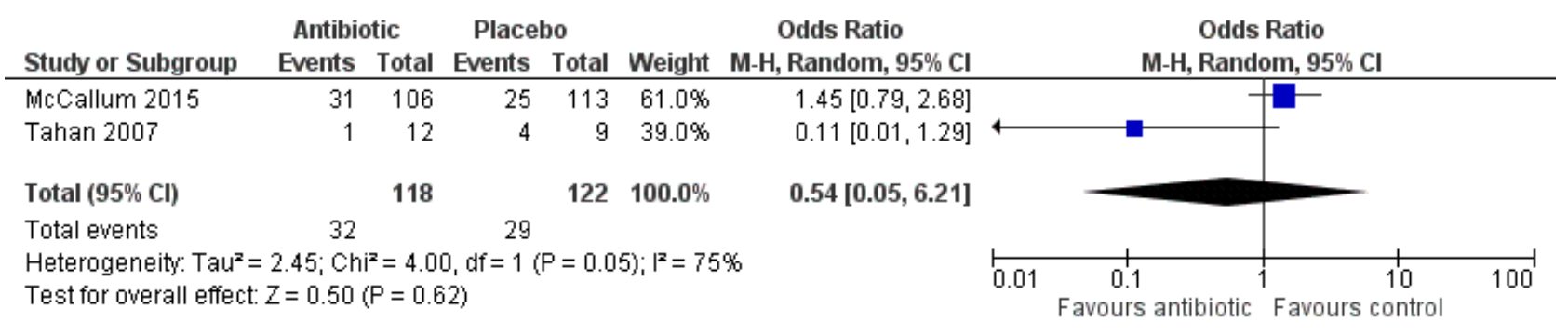




\section{Secondary outcomes}

Mean differences in cough indices (e.g. cough diary, frequency, or scores; quality of life)

Nil studies reported this outcome.

Mean differences in wheeze indices (e.g. cough diary, frequency, or scores; quality of life)

Nil studies reported this outcome.

\section{Proportion of participants with wheeze (within six months of intervention)}

Both studies (Tahan 2007; McCallum 2015) reported wheeze within six months of the intervention. In Tahan 2007, five children presented to hospital with a wheezing illness (clarithromycin group $n=1$; placebo group $n=4$ ). McCallum 2015 reported wheeze at two time points: the first at the day 21 clinical review, where wheeze was documented in 22 children (azithromycin group $n=11$; placebo group $\mathrm{n}=11$ ), the second at a medical chart review performed at six months, where 60 children were re-admitted to hospital with a wheezing-associated illness. Data showed no statistically significant differences between treatment groups for the outcome of reported wheeze at six months (OR $0.78,95 \% \mathrm{Cl} 0.35$ to 1.73 ). Results revealed statistical heterogeneity for this outcome $\left(1^{2}=\right.$ $75 \% ; P=0.05$ ), likely due to the small number of participants included in Tahan 2007. Random-effects analysis revealed that differences between groups remained non-significant (OR 0.47, $95 \% \mathrm{Cl} 0.06$ to 3.95; Analysis 1.3; Figure 6).

Figure 6. Forest plot of comparison: 1 Prevention of post-bronchiolitis syndrome (antibiotics vs placebo), outcome: 1.3 Proportion of participants with wheeze (within 6 months of intervention).

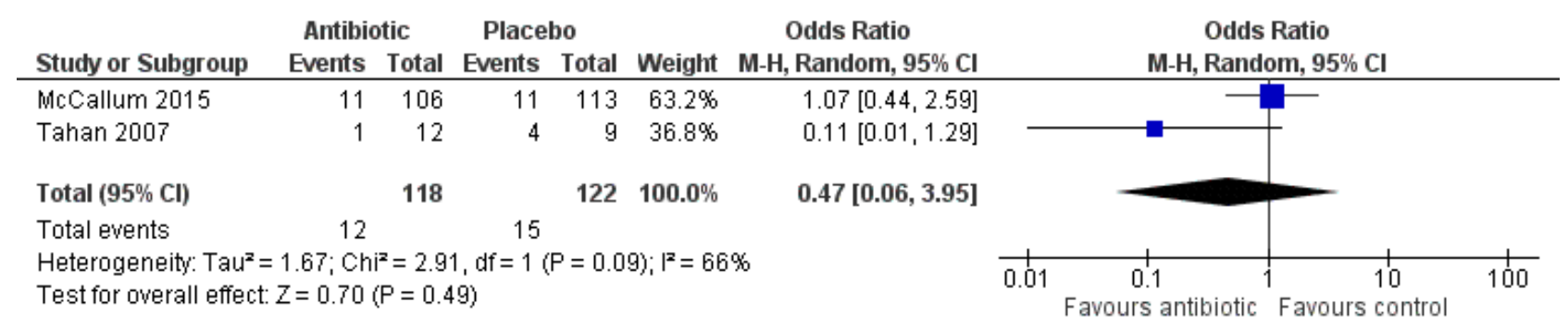

\section{Adverse events (e.g. proportion of participants requiring new medications or developing pneumonia)}

Tahan 2007, did not report adverse events. McCallum 2015 reported three adverse events. From the azithromycin group, one infant presented to hospital with vomiting and diarrhoea, and a second vomited the trial medication. One infant in the placebo group presented to hospital with wheezing and rash. All three recovered and remained in the study.

\section{Bacterial resistance}

Only one study reported on bacterial antimicrobial resistance (McCallum 2015). In this study, bacterial antimicrobial resistance was measured at 48 hours after enrolment and included (e.g. Streptococcus pneumoniae, non-typableHaemophilus influenza, Moraxella catarrhalis, and Staphylococcus aureus) (McCallum 2015). We have not analysed bacterial resistance for this review, as results of this analysis are not clinically meaningful for post-acute bronchiolitis.

\section{Subgroup analysis}

We were unable to perform any subgroup analysis for either study (Tahan 2007; McCallum 2015).

\section{Sensitivity analysis}

Data were insufficient to allow performance of any sensitivity analysis.

\section{DISCUSSION}

\section{Summary of main results}

This review updated a study from the previous review (McCallum 2012) and added a new study (McCallum 2015). Thus, our updated review consists of two randomised controlled trials (RCTs) with 249 children hospitalised with bronchiolitis. One was a singlecentre study, and the other a multi-centre study with duration of six months. We were unable to analyse many primary and secondary outcomes owing to lack of available data. Investigators reported improvement in cure rate and in the proportion of infants with wheeze by six months but found no statistically significant between-group differences. A single study examined bacterial antimicrobial resistance only at 48 hours, thus data were not relevant for the post-acute phase (i.e. we did not perform analysis). This review is limited by the small numbers of available trials and participants. Thus, we cannot provide new evidence to support (or refute) the efficacy of antibiotics for reducing or treating persistent symptoms within six months of acute bronchiolitis.

\section{Overall completeness and applicability of evidence}

Use of antibiotics for treatment of bronchiolitis in the acute phase, is recommended only when a secondary bacterial infection is suspected (Ralston 2014; NICE 2015). For some populations, however, the burden of prolonged respiratory symptoms such as wheezing and cough and respiratory re-admissions after an acute episode of bronchiolitis is increasing and is associated with ongoing poorer respiratory outcomes (e.g. future diagnosis of bronchiectasis) (McCallum 2016).

The findings of our review are limited by few eligible studies, high rates of attrition (Tahan 2007), and lack of available data, 
precluding the possibility of combining outcomes for metaanalysis. The data presented in Tahan 2007 suggest that antibiotics may be effective in preventing ongoing respiratory symptoms after acute bronchiolitis. However, when these results are combined with those reported by the larger McCallum 2015 study, intentionto-treat (ITT) analysis reveals that none of the clinical outcomes showed statistically significant differences between treatment groups. Given the small numbers of included studies and participants, a type 1 error (inadequate sample size) may be present. Also, review authors noted differences between studies in methods of reporting. Thus, we downgraded the level of evidence in Summary of findings for the main comparison.

Both studies included hospitalised children, hence data may not be relevant for community-treated children. Although children with severe bronchiolitis (i.e. hospitalised children) are more likely to have persistent symptoms than those with milder bronchiolitis (i.e. community-treated children), no studies have examined this.

This review was also limited by the fact that only one study reported on adverse events, including antibiotic resistance (McCallum 2015). By 48 hours, few children harboured nasal bacteria that were antibiotic resistant, and data showed no differences between treatment groups. However, data were limited to 48 hours after admission to hospital; this study ideally would have assessed antibiotic resistance at the day 21 review, but the study design precluded longer-term assessment.

Both studies used macrolide antibiotics, but it remains unknown whether a non-macrolide antibiotic would have produced similar findings. Some strains of common lower airway respiratory bacteria (Streptococcus pneumoniae, Haemophilus influenzae, Moraxella catarrhalis) are macrolide resistant, and it possible that another antibiotic type (e.g. amoxicillin-clavulanate) may yield different findings. In addition to being an anti-microbial, macrolides have additional benefits (such as immunomodulatory) and thus data presented here cannot be extrapolated to non-macrolide antibiotics. Also, in light of the fact that investigators commenced antibiotics at the onset of acute bronchiolitis, Tahan 2007 and McCallum 2015 could be classified as examining 'prevention' of post-bronchiolitis syndrome. We found no eligible studies that examined 'treatment' of post-bronchiolitis syndrome (i.e. no studies examined the efficacy of antibiotics for improving clinical outcomes at the point of development of chronic cough, defined by international chronic cough guidelines as > 4 weeks (Leconte 2008; Chang 2017)).

\section{Quality of the evidence}

In Summary of findings for the main comparison, we have summarised available evidence for our main primary and some secondary outcomes related to the effectiveness of antibiotics following acute bronchiolitis. The quality of the evidence was low owing to small numbers of studies and participants and high rates of attrition in Tahan 2007, hence we cannot be confident of the effect estimate in spite of the high quality of one of the studies.

\section{Potential biases in the review process}

Three of the authors of this review were senior authors on the McCallum 2015 paper. EJP sought additional data through direct contact with Dr. McCallum, and the Cochrane Editor (Dr. Cates) checked the data. Review author Erin Plumb, who was not involved in the McCallum 2015 trial, performed risk of bias and GRADE assessments.

\section{Agreements and disagreements with other studies or reviews}

We are not aware of any other reviews or studies against which these results can be compared. Updated high-quality bronchiolitis guidelines (Ralston 2014; NICE 2015) did not include interventions for post-bronchiolitis syndrome. The findings of our review are similar to findings for acute bronchiolitis (Spurling 2011); Spurling found "minimal evidence to support the use of antibiotics for acute bronchiolitis," although the Spurling review did not include the new study.

\section{AUTHORS' CONCLUSIONS}

\section{Implications for practice}

Current evidence is insufficient to inform whether antibiotics should be used to treat or prevent persistent respiratory symptoms during the post-acute bronchiolitis phase (> 14 days).

\section{Implications for research}

Future RCTs must evaluate the efficacy of antibiotics for reducing persistent respiratory symptoms, especially in settings where the morbidity of acute bronchiolitis is high, such as in indigenous communities in Australia, New Zealand, and the USA, and in lowincome countries, where risk of chronic lung disease is high. Future studies could focus primarily on prevention (i.e. antibiotics started in acute phase $<14$ days) or on treatment (when children have persistent symptoms). They should employ a parallel design, and should be placebo-controlled and double-blinded. Studies should address macrolide and non-macrolide antibiotics separately, and should consider prevention of persistent symptoms separately from treatment of ongoing symptoms. In the latter case, a longer course of antibiotics will likely be required in light of the Cochrane review on antibiotics for persistent wet cough in children (Marchant 2005) and current data on protracted bacterial bronchitis (Marchant 2012). Also, no trials have examined use of antibiotics after four weeks (the international definition of chronic cough in children (Leconte 2008; Chang 2017)) for persistent symptoms post bronchiolitis, and such research is needed to inform clinical practice. Studies should include microbiological data (on both viruses and bacteria) that would complement clinical outcomes, and should include both hospitalised and community-treated children; they should report on validated outcomes as assessed by both subjective and objective measurements.

\section{ACK N O WLEDGEMENTS}

We thank Dr. Chris Cates, Dr. Emma Dennett, Jessica Thomas, and Emma Jackson for support for the protocol and the review. We also thank Elizabeth Stovold from the Cochrane Airways Group for performing the searches.

Dr. Chris Cates served as the Editor for this review and commented critically on the review.

The Background and Methods sections of this review are based on a standard template used by Cochrane Airways. 
This project was supported by the National Institute for Health Research (NIHR) via Cochrane Infrastructure funding to the Cochrane Airways Group. The views and opinions expressed therein are those of the review authors and do not necessarily reflect those of the Systematic Reviews Programme, NIHR, NHS, or the Department of Health. 


\section{RE F E R E N C E S}

\section{References to studies included in this review}

McCallum 2015 \{published data only\}

* McCallum GB, Morris PS, Grimwood K, Maclennan C, White AV, Chang AB, et al. Three-weekly doses of azithromycin for indigenous infants hospitalized with bronchiolitis: a multicentre, randomized, placebo-controlled trial. Frontiers in Pediatrics 2015;3:1-9.

\section{Tahan 2007 \{published data only\}}

Tahan F, Ozcan A, Koc N. Clarithromycin in the treatment of RSV bronchiolitis: a double-blind, randomised, placebo-controlled trial. European Respiratory Journal 2007;29:91-7.

\section{References to studies excluded from this review}

Beigelman 2015 \{published data only\}

* Beigelman A, Isaacson-Schmid M, Sajol G, Baty J, Rodrigues OM, Leege $\mathrm{E}$, et al. Randomized trial to evaluate azithromycin's effects on serum and upper airway IL-8 levels and recurrent wheezing in infants with respiratory syncytial virus bronchiolitis. Journal of Allergy and Clinical Immunology 2015;135(5):1171-8e1. [CN-01087161; CN-01130880; CN-01136644; P30 CA091842]

\section{Friis 1984 \{published data only\}}

Friis B, Anderson P, Brenoe E, Hornsleth A, Jensen A, Knudsen F, et al. Antibiotic treatment of pneumonia and bronchiolitis - a prospective randomised study. Archives of Disease in Childhood 1984;59:1038-45.

\section{Kabir 2009 \{published data only\}}

Kabir A, Mollah A, Anwar K, Rahman A, Amin R, Rahman M. Management of bronchiolitis without antibiotics: a multicentre randomized control trial in Bangladesh. Acta Paediatrica 2009;98:1593-9.

\section{Kneyber 2008 \{published data only\}}

Kneyber MC, Woensel JB, Uitjendaal E, Uiterwaal C, Kimpen J. Azithromycin does not improve disease course in hospitalized infants with respiratory syncytial virus (RSV) lower respiratory tract disease: a randomized equivalence trial. Pediatric Pulmonology 2008;43:142-9.

\section{Mazumder 2009 \{published data only\}}

Mazumder M, Hossain M, Kabir A. Management of bronchiolitis with or without antibiotics - a randomized control trial. Journal of Bangladesh College of Physicians and Surgeons 2009;27:63-9.

\section{McCallum 2013 \{published data only\}}

* McCallum GB, Morris PS, Chatfield MD, Maclennan C, White AV, Chang AB. A single dose of azithromycin does not improve clinical outcomes of children hospitalised with bronchiolitis: a randomised, placebo-controlled trial. PloS One 2013;8(9):1-9. randomized, double-blinded, and placebo-controlled clinical trial. Journal of Paediatrics 2012;161(6):1104-8. [RBR-257ZBC; SN-1099-0496]

\section{Additional references}

\section{Bailey 2009}

Bailey EJ, Maclennan C, Morris PS, Kruske SG, Brown N, Chang AB. Risks of severity and readmission of indigenous and non-indigenous children hospitalised for bronchiolitis. Journal of Paediatrics and Child Health 2009;45:593-7.

\section{Blom-Danielle 2007}

Blom-Danielle JM, Ermers M, Bont L, van-Woensel-Job BM, van-Aalderen-Wim MC. Inhaled corticosteroids during acute bronchiolitis in the prevention of post-bronchiolitic wheezing. Cochrane Database of Systematic Reviews 2007, Issue 1. [DOI: 10.1002/14651858.CD004881.pub3]

\section{Carroll 2009}

Carroll N, Wu P, Gebretsadik T, Griffin MR, Dupont WD, Mitchel EF, et al. The severity-dependent relationship of infant bronchiolitis on the risk and morbidity of early childhood asthma. Journal of Allergy and Clinical Immunology 2009;123:1055-61.

\section{Chang 2009}

Chang AB, Chang CC, O'Grady K, Torzillo PJ. Lower respiratory tract infections. Pediatric Clinics of North America 2009;56(6):1303-21.

\section{Chang 2017}

Chang AB, Oppenheimer JJ, Weinberger M, Rubin BK, Weir K, Irwin RS. Management of children with chronic wet cough and protracted bacterial bronchitis: CHEST Guideline and Expert Panel Report. Chest 2017;151(4):884-90.

\section{Didierlaurent 2008}

Didierlaurent A, Goulding J, Patel S, Snelgrove R, Low L, Bebien M, et al. Sustained desensitization to bacterial Tolllike receptor ligands after resolution of respiratory influenza infection. Journal of Experimental Medicine 2008;205(2):323-9.

\section{Fox 1999}

Fox GF, Everard ML, Marsh MJ, Milner AD. Randomised controlled trial of budesonide for the prevention of postbronchiolitis wheezing. Archives of Disease in Childhood 1999;80(4):343-7.

\section{Giamarellos-Bourboulis 2008}

Giamarellos-Bourboulis EJ. Macrolides beyond the conventional antimicrobials: a class of potent immunomodulators. International Journal of Antimicrobial Agents 2008;31(1):12-20.

Pinto 2012 \{published data only\}

Pinto LA, Pitrez PM, Luisi F, Mello PP, Gerhardt M, Marostica PJ. Azithromycin therapy in hospitalized infants with acute bronchiolitis is not associated with better clinical outcomes: a 


\section{GRADEpro GDT 2015}

GRADEpro GDT. GRADEpro Guideline Development Tool [Software]. McMaster University, 2015 (developed by Evidence Prime, Inc.). gradepro.org.

\section{Halfhide 2008}

Halfhide C, Smythe RL. Innate immune response and bronchiolitis and preschool recurrent wheeze. Paediatric Respiratory Reviews 2008;9(4):251-62.

\section{Higgins 2011}

Higgins JPT, Green S (editors). Cochrane Handbook for Systematic Reviews of Interventions Version 5.1.0 [March 2011]. The Cochrane Collaboration, 2011. www.cochranehandbook.org.

\section{Kim 2010}

Kim CK, Choi J, Kim HB, Callaway Z, Shin BM, Kim JT, et al. A randomized intervention of montelukast for post-bronchiolitis: effect on eosinophil degranulation. Journal of Pediatrics 2010;156(5):749-54.

\section{Leach 1994}

Leach AJ, Boswell JB, Asche V, Nienhuys TG, Mathews JD. Bacterial colonization of the nasopharynx predicts very early onset and persistence of otitis media in Australian aboriginal infants. Pediatric Infectious Disease Journal 1994;13(11):983-9.

\section{Leconte 2008}

Leconte S, Paulus D, Degryse J. Prolonged cough in children: a summary of the Belgian primary care clinical guideline. Primary Care Respiratory Journal 2008;17(4):206-11.

\section{Marchant 2005}

Marchant JM, Morris P, Gaffney J, Chang AB. Antibiotics for prolonged moist cough in children. Cochrane Database of Systematic Reviews 2005, Issue 4. [DOI: 10.1002/14651858.CD004822.pub2]

\section{Marchant 2012}

Marchant JM, Masters IB, Champion A, Petsky HL, Chang AB. Randomised controlled trial of amoxycillin-clavulanate in children with chronic wet cough. Thorax 2012;67(8):689-93. [DOI: 10.1136/thoraxjnl-2011-201506]

\section{McCallum 2012}

McCallum GB, Morris PS, Chang AB. Antibiotics for persistent cough or wheeze following acute bronchiolitis in children. Cochrane Database of Systematic Reviews 2012, Issue 12. [DOI: 10.1002/14651858.CD009834.pub2]

\section{McCallum 2016}

McCallum GB, Chatfield MD, Morris PS, Chang AB. Risk factors for adverse outcomes of Indigenous infants hospitalized with bronchiolitis. Pediatric Pulmonology 2016;51:613-23.

\section{McCullers 2006}

McCullers JA. Insights into the interaction between influenza virus and pneumococcus. Clinical Microbiology Reviews 2006;19:571-82.

\section{NICE 2015}

National Institute for Health and Care Excellence (NICE). Bronchiolitis: diagnosis and management in children. www.nice.org.uk/Guidance/NG9 2015.

\section{Ralston 2014}

Ralston SL, Lieberthal AS, Meissner HC, Alverson BK, Baley JE, Gadomski AM, et al. Clinical practice guideline: the diagnosis, management, and prevention of bronchiolitis. Pediatrics 2014;134:e1474-e1502.

\section{RevMan 2014 [Computer program]}

The Nordic Cochrane Centre, The Cochrane Collaboration. Review Manager (RevMan). Version 5.3. Copenhagen: The Nordic Cochrane Centre, The Cochrane Collaboration, 2014.

\section{SIGN 2006}

Scottish Intercollegiate Guidelines Network (SIGN). Bronchiolitis in children: a national clinical guideline. Archives of Disease in Childhood Education and Practice Edition 2006;91:1-46.

\section{Sigurs 2000}

Sigurs N, Bjarnason R, Sigurbergsson F, Kjellman B. Respiratory syncytial virus bronchiolitis in infancy is an important risk factor for asthma and allergy at age 7. American Journal of Respiratory and Critical Care Medicine 2000;161:1501-7.

\section{Spurling 2011}

Spurling GK, Doust J, Del Mar CB, Eriksson L. Antibiotics for bronchiolitis in children. Cochrane Database of Systematic Reviews 2011, Issue 6. [DOI: 10.1002/14651858.CD005189.pub3]

\section{Su 2014}

Su SC, Chang AB. Improving the management of children with bronchiolitis: the updated American Academy of Pediatrics clinical practice guideline. Chest 2014;6:1428-30.

\section{Swingler 2000}

Swingler GH, Hussey GD, Zwarenstein M. Duration of illness in ambulatory children diagnosed with bronchiolitis. Archives of Pediatrics and Adolescent Medicine 2000;154:997-1000.

\section{Wong 2005}

Wong JY, Rutman A, O'Callaghan C. Recovery of the ciliated epithelium following acute bronchiolitis in infancy. Thorax 2005;60(7):582-7.

\section{Zarogoulisidis 2011}

Zarogoulidis P, Papanas N, Kioumis I, Chatzaki E, Maltezos E, Zarogoulidis K. Macrolides: from in vitro anti-inflammatory and immunomodulatory properties to clinical practice in respiratory diseases. European Journal of Clinical Pharmacology 2011;67:1-25.

* Indicates the major publication for the study 
CHARACTERISTICS OF STUDIES

Characteristics of included studies [ordered by year of study]

Tahan 2007

\begin{tabular}{ll}
\hline Methods & Double-blind, placebo-controlled, parallel-group, randomised study \\
\hline Participants & Inclusion criteria: \\
- Infants $\leq 7$ months \\
- Hospitalised with first-time episode of wheezing requiring hospitalisation and with respiratory syncy- \\
tial virus-confirmed bronchiolitis \\
Exclusion criteria: \\
- Cardiac disease \\
- Cystic fibrosis \\
- Chronic neonatal lung disease associated with prematurity \\
tation to hospital
\end{tabular}

Number screened: not stated

Number refused: not stated

Number randomised: total $n=30$ (intervention group $n=15$ and control group $n=15$ )

\begin{tabular}{ll}
\hline Interventions & Oral clarithromycin $(15 \mathrm{mg} / \mathrm{kg} / \mathrm{d})$ or placebo $(15 \mathrm{mg} / \mathrm{kg} / \mathrm{d})$ daily for 3 weeks \\
\hline Outcomes & Primary outcomes \\
1. Length of hospital stay \\
2. Supplemental oxygen \\
3. Wheeze \\
Secondary outcomes \\
1. Decrease in plasma concentrations (interleukin-4, interleukin-8, eotaxin) \\
2. Enhanced production of interferon-gamma
\end{tabular}

\begin{tabular}{ll}
\hline Notes & Single site \\
& Small sample size \\
& High attrition \\
& Funding: not stated \\
\hline
\end{tabular}

\section{Risk of bias}

\begin{tabular}{lll}
\hline Bias & Authors' judgement & Support for judgement \\
\hline $\begin{array}{l}\text { Random sequence genera- } \\
\text { tion (selection bias) }\end{array}$ & Unclear risk & $\begin{array}{l}\text { No information on sequence generation provided. Paper describes that partic- } \\
\text { ipants were "randomised by a single study nurse" }\end{array}$ \\
\hline $\begin{array}{l}\text { Allocation concealment } \\
\text { (selection bias) }\end{array}$ & Unclear risk & $\begin{array}{l}\text { No information provided on how the study nurse randomised each participant } \\
\text { and how concealment was maintained }\end{array}$ \\
\hline $\begin{array}{l}\text { Blinding of participants } \\
\text { and personnel (perfor- } \\
\text { mance bias) }\end{array}$ & Low risk & $\begin{array}{l}\text { Participants and families remained blinded to randomisation until end of } \\
\text { study }\end{array}$ \\
\hline
\end{tabular}


Tahan 2007 (Continued)

All outcomes

\begin{tabular}{|c|c|c|}
\hline $\begin{array}{l}\text { Blinding of outcome as- } \\
\text { sessment (detection bias) }\end{array}$ & Low risk & $\begin{array}{l}\text { Paper described that investigators remained blinded to randomisation until } \\
\text { end of study }\end{array}$ \\
\hline
\end{tabular}

All outcomes

\begin{tabular}{|c|c|c|}
\hline $\begin{array}{l}\text { Incomplete outcome data } \\
\text { (attrition bias) } \\
\text { All outcomes }\end{array}$ & Unclear risk & $\begin{array}{l}30 \text { participants were enrolled and randomised. During the study phase, } 9 \text { were } \\
\text { excluded ( } 30 \%) \text { because they had received corticosteroids. Groups and out- } \\
\text { comes of these infants were not reported }\end{array}$ \\
\hline
\end{tabular}

All outcomes comes of these infants were not reported

\begin{tabular}{lll}
$\begin{array}{l}\text { Selective reporting (re- } \\
\text { porting bias) }\end{array}$ & Unclear risk & $\begin{array}{l}\text { The results table appears to show analysis including only children remaining } \\
\text { in the trial }(n=21) . \text { ITT was not used }\end{array}$ \\
\hline Other bias & Unclear risk & $\begin{array}{l}\text { It is unclear whether the trial was registered, and if outcomes were selected a } \\
\text { priori }\end{array}$
\end{tabular}

\section{McCallum 2015}

Methods Multi-centre, double-blinded, placebo-controlled, parallel-group, randomised study

\section{Participants}

\section{Inclusion criteria:}

- Indigenous ethnicity defined as Aboriginal, Tores Strait Islander, Maori, and/or Pacifici Islander

- Infants aged $\leq 24$ months

- Hospitalised with a clinical diagnosis of bronchiolitis

- Consented within 24 hours of hospitalisation

- Caregivers required to have mobile phone

\section{Exclusion criteria:}

- Chronic lung disease or bronchiectasis

- Current diagnosis of gastroenteritis

- Received azithromycin in past 7 days

- Liver impairment

- Cyanotic congenital heart disease

- Received oxygen for longer than 24 hours in admitting hospital

Number screened: $n=698$ ( $n=479$ excluded for various reasons)

Number refused: $n=89$

Number randomised: total $n=219$ (intervention group $n=106$ and control group $n=113$ )

\begin{tabular}{ll}
\hline Interventions & Oral azithromycin ( $30 \mathrm{mg} / \mathrm{kg}$ once weekly) or placebo $(30 \mathrm{mg} / \mathrm{kg}$ once weekly) for 3 weeks \\
\hline Outcomes & Primary outcomes: \\
- Length of hospital stay \\
- Duration of supplemental oxygen use \\
Secondary outcomes: \\
- Respiratory symptoms and signs at day 21 \\
- Respiratory rehospitalisation (within 6 months of discharge) \\
- lected at admission and 48 hours later)
\end{tabular}


McCallum 2015 (Continued)

Notes

International RCT between Australia and New Zealand

RCT was registered with the Australian and New Zealand Clinical Trials Registry (ACTRN1261000036099)

Funding: National Health and Medical Research Council (605809)

\section{Risk of bias}

\begin{tabular}{|c|c|c|}
\hline Bias & Authors' judgement & Support for judgement \\
\hline $\begin{array}{l}\text { Random sequence genera- } \\
\text { tion (selection bias) }\end{array}$ & Low risk & $\begin{array}{l}\text { Independent statistician used a computer-generated, permuted block design } \\
\text { to generate randomisation sequences }\end{array}$ \\
\hline $\begin{array}{l}\text { Allocation concealment } \\
\text { (selection bias) }\end{array}$ & Low risk & Sealed opaque envelopes concealed treatment allocation \\
\hline $\begin{array}{l}\text { Blinding of participants } \\
\text { and personnel (perfor- } \\
\text { mance bias) } \\
\text { All outcomes }\end{array}$ & Low risk & $\begin{array}{l}\text { All participants, family, assessor, and hospital staff remained blinded during } \\
\text { the study }\end{array}$ \\
\hline $\begin{array}{l}\text { Blinding of outcome as- } \\
\text { sessment (detection bias) } \\
\text { All outcomes }\end{array}$ & Low risk & $\begin{array}{l}\text { Neither the study team (researchers hospital staff) nor parents were aware of } \\
\text { assigned treatment groups until data analysis was completed }\end{array}$ \\
\hline $\begin{array}{l}\text { Incomplete outcome data } \\
\text { (attrition bias) } \\
\text { All outcomes }\end{array}$ & Low risk & $\begin{array}{l}219 \text { participants were randomised and intention-to-treat analysis was per- } \\
\text { formed }\end{array}$ \\
\hline $\begin{array}{l}\text { Selective reporting (re- } \\
\text { porting bias) }\end{array}$ & Low risk & All participants were analysed as 'intention-to-treat' \\
\hline Other bias & Low risk & $\begin{array}{l}\text { The trial was registered. Details of adverse events were reported - none of the } \\
\text { participants discontinued the trial }\end{array}$ \\
\hline
\end{tabular}

Characteristics of excluded studies [ordered by study ID]

\begin{tabular}{ll}
\hline Study & Reason for exclusion \\
\hline Beigelman 2015 & In this RCT, treatment occurred during the acute phase of bronchiolitis (e.g. $\leq 14$ days) \\
\hline Friis 1984 & $\begin{array}{l}\text { This open randomised trial included children up to } 62 \text { months of age with a diagnosis of pneumo- } \\
\text { nia; treatment provided up to } 6 \text { days did not include use of antibiotics beyond the acute period }\end{array}$ \\
\hline Kabir 2009 & In this RCT, the treatment period lasted only up to 7 days \\
\hline Kneyber 2008 & In this RCT, the treatment period lasted only up to 3 days \\
\hline Mazumder 2009 & $\begin{array}{l}\text { Length of treatment period for this RCT is not clear. Analysis describes up to } 5 \text { days, thus not eligi- } \\
\text { ble for post-acute bronchiolitis }\end{array}$ \\
\hline McCallum 2013 & In this RCT, treatment was provided during the acute phase of bronchiolitis (i.e. $\leq 14$ days) \\
\hline Pinto 2012 & In this RCT, treatment was provided during the acute phase of bronchiolitis (i.e. $\leq 14$ days)
\end{tabular}


$\mathrm{RCT}$ : randomised controlled trial

\section{DATA AND ANALYSES}

Comparison 1. Prevention of post-bronchiolitis syndrome (antibiotics vs placebo)

\begin{tabular}{lllll}
\hline Outcome or subgroup title & No. of studies & $\begin{array}{l}\text { No. of partici- } \\
\text { pants }\end{array}$ & Statistical method & Effect size \\
\hline $\begin{array}{l}\text { 1 Number of participants who were not } \\
\text { cured at follow-up (up to 6 month) }\end{array}$ & 2 & 249 & $\begin{array}{l}\text { Odds Ratio (M-H, Fixed, } \\
95 \% \mathrm{Cl})\end{array}$ & $0.69[0.37,1.28]$ \\
\hline $\begin{array}{l}2 \text { Number of participants who were rehospi- } \\
\text { talised within 6 months }\end{array}$ & 2 & 240 & $\begin{array}{l}\text { Odds Ratio (M-H, Ran- } \\
\text { dom, 95\% Cl) }\end{array}$ & $0.54[0.05,6.21]$ \\
\hline $\begin{array}{l}\text { 3 Proportion of participants with wheeze } \\
\text { (within 6 months of intervention) }\end{array}$ & 2 & 240 & Odds Ratio (M-H, Ran- & $0.47[0.06,3.95]$ \\
\hline
\end{tabular}

Analysis 1.1. Comparison 1 Prevention of post-bronchiolitis syndrome (antibiotics vs placebo), Outcome 1 Number of participants who were not cured at follow-up (up to 6 months).

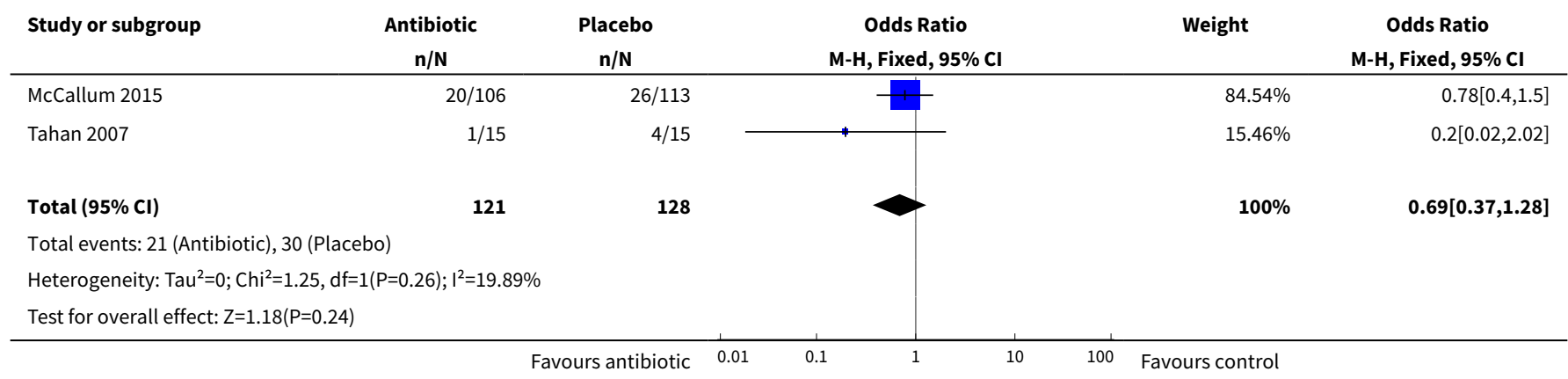

Analysis 1.2. Comparison 1 Prevention of post-bronchiolitis syndrome (antibiotics vs placebo), Outcome 2 Number of participants who were rehospitalised within 6 months.

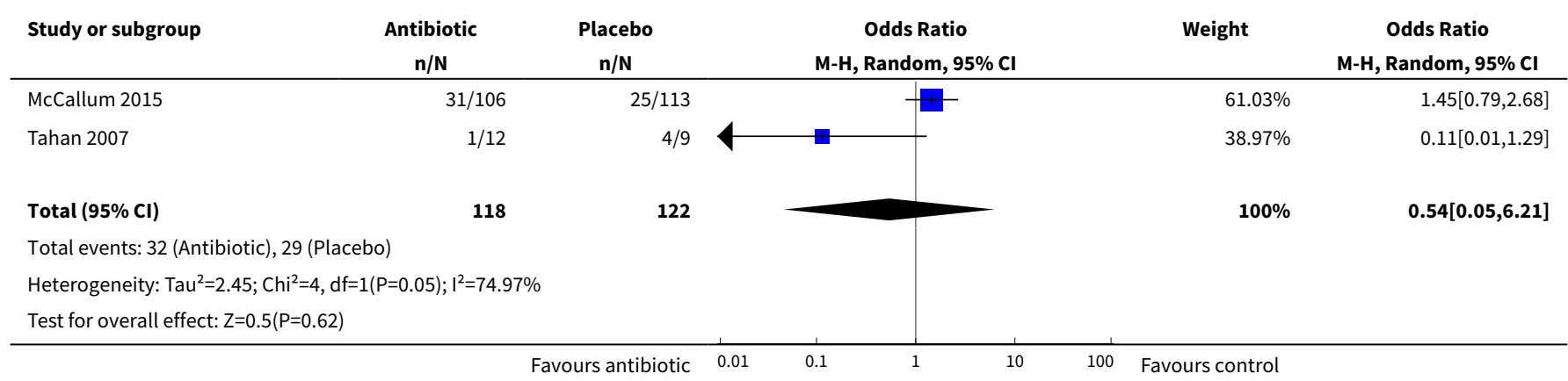


Analysis 1.3. Comparison 1 Prevention of post-bronchiolitis syndrome (antibiotics vs placebo), Outcome 3 Proportion of participants with wheeze (within 6 months of intervention).

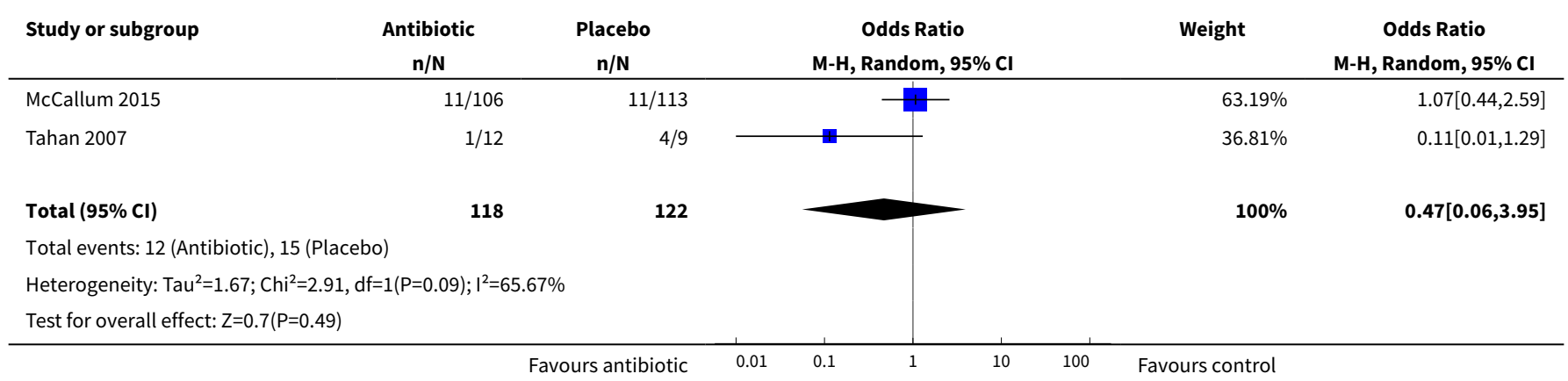

\section{APPENDICES}

\section{Appendix 1. Database search strategies}

\section{CENTRAL (the Cochrane Library)}

\#1 MeSH descriptor Bronchiolitis explode all trees

\#2 MeSH descriptor Respiratory Syncytial Virus Infections explode all trees

\#3 bronchioliti*:ti,ab,kw

\#4 RSV*:ti,ab,kw

\#5 (\#1 OR \#2 OR \#3 OR \#4)

\#6 MeSH descriptor Cough, this term only

\#7 MeSH descriptor Respiratory Sounds explode all trees

\#8 cough*:ti,ab,kw

\#9 wheez ${ }^{\star}: \mathrm{ti}, \mathrm{ab}, \mathrm{kw}$

\#10 post-viral*:ti,ab,kw

$\# 11$ post-acute ${ }^{\star}: \mathrm{ti}, \mathrm{ab}, \mathrm{kw}$

\#12 Any MeSH descriptor with qualifier: CO

\#13 MeSH descriptor Recurrence explode all trees

\#14 (\#6 OR \#7 OR \#8 OR \#9 OR \#10 OR \#11 OR \#12 OR \#13)

\#15 (\#5 AND \#14)

\#16 post-RSV*:ti,ab,kw

\#17 post-bronchiolit*:ti,ab,kw

\#18 (\#15 OR \#16 OR \#17)

\#19 MeSH descriptor Anti-Bacterial Agents explode all trees

\#20 antibiotic ${ }^{*}: \mathrm{ti}, \mathrm{ab}, \mathrm{kw}$

\#21 MeSH descriptor Macrolides explode all trees 
\#22 (macrolide* or azithromycin or clarithromycin or erythromycin or roxithromycin or spiramycin):ti,ab,kw

\#23 (penicillin or amoxicillin or amoxycillin or ampicillin or benzylpenicillin or cloxacillin or dicloxacillin or flucloxacillin or piperacillin or ticarcillin or sulbactam):ti,ab,kw

\#24 (cephalosporin ${ }^{\star}$ or cephalexin or cephaclor or cefaclor or cefepime or cefotaxime or cephamycin* or cefotetan or cefoxitin or cefmetazole or cefpirome or cefpodoxime or ceftazidime or ceftriaxone or cephamandole or cephazolin):ti,ab,kw

\#25 (fluoroquinolone* or ciprofloxacin or enoxacin or norfloxacin or ofloxacin or pefloxacin or fleroxacin or levofloxacin or moxifloxacin):ti,ab,kw

\#26 (tetracycline* or doxycycline or methacycline or minocycline):ti,ab,kw

\#27 (amikacin or gentamicin or neomycin or netilmicin):ti,ab,kw

\#28 (clindamycin or lincomycin):ti,ab,kw

\#29 (chloramphenicol or amantadine or cotrimoxazole or trimethoprim):ti,ab,kw

\#30 (\#19 OR \#20 OR \#21 OR \#22 OR \#23 OR \#24 OR \#25 OR \#26 OR \#27 OR \#28 OR \#29)

\#31 (\#18 AND \#30)

\#32 MeSH descriptor Child explode all trees

\#33 MeSH descriptor Pediatrics explode all trees

\#34 MeSH descriptor Infant explode all trees

\#35 MeSH descriptor Adolescent, this term only

\#36 paediatric $^{\star}$ or paediatric ${ }^{\star}$ or child ${ }^{\star}$ or adolescen* or infant $^{\star}$ or young* or preschool* or pre-school* or newborn* or new-born ${ }^{\star}$ or $^{*}$ neonat ${ }^{\star}$ or neo-nat $\left.{ }^{\star}\right):$ ti,ab,kw

\#37 (\#32 OR \#33 OR \#34 OR \#35 OR \#36)

\#38 (\#31 AND \#37)

\section{MEDLINE (Ovid)}

1. exp Bronchiolitis/

2. Respiratory Syncytial Virus Infections/

3. bronchioliti\$.tw.

4. RSV\$.tw.

5. or/1-4

6. Cough/

7. Respiratory Sounds/

8. cough\$.tw.

9. wheez\$.tw.

10. post-viral\$.tw.

11. post-acute\$.tw.

12. co.fs.

13. Recurrence/

14. or/6-13

15.5 and 14

Antibiotics for persistent cough or wheeze following acute bronchiolitis in children (Review) 
16. post-RSV\$.tw.

17. post-bronchiolit\$.tw.

18. 15 or 16 or 17

19. exp Anti-Bacterial Agents/

20. antibiotic\$.tw.

21. exp Macrolides/

22. (macrolide\$ or azithromycin or clarithromycin or erythromycin or roxithromycin or spiramycin).tw.

23. (penicillin\$ or amoxicillin or amoxycillin or ampicillin or benzylpenicillin or cloxacillin or dicloxacillin or flucloxacillin or piperacillin or ticarcillin or sulbactam).tw.

24. (cephalosporin\$ or cephalexin or cephaclor or cefaclor or cefepime or cefotaxime or cephamycin\$ or cefotetan or cefoxitin or cefmetazole or cefpirome or cefpodoxime or ceftazidime or ceftriaxone or cephamandole or cephazolin).tw.

25. (fluoroquinolone\$ or ciprofloxacin or enoxacin or norfloxacin or ofloxacin or pefloxacin or fleroxacin or levofloxacin or moxifloxacin).tw.

26. (tetracycline\$ or doxycycline or methacycline or minocycline).tw.

27. (amikacin or gentamicin or neomycin or netilmicin).tw.

28. (clindamycin or lincomycin).tw.

29. (chloramphenicol or amantadine or cotrimoxazole or trimethoprim).tw.

30. or/19-29

31. 18 and 30

32. $\exp$ Child/

33. exp Pediatrics/

34. exp infant/

35. exp adolescent/

36. (paediatric $\$$ or paediatric $\$$ or child\$ or adolescen\$ or infant $\$$ or young $\$$ or preschool\$ or pre-school\$ or newborn\$ or new-born\$ or neonat\$ or neo-nat\$).tw.

37. or/32-36

38. 31 and 37

39. (clinical trial or controlled clinical trial or randomised controlled trial).pt.

40. (randomised or randomised).ab,ti.

41. placebo.ab,ti.

42. dt.fs.

43. randomly.ab,ti.

44. trial.ab,ti.

45. groups.ab,ti.

46. or/39-45

47. Animals/

48. Humans/

Antibiotics for persistent cough or wheeze following acute bronchiolitis in children (Review) 
49. 47 not (47 and 48)

50.46 not 49

51. 38 and 50

\section{Embase (Ovid)}

1. exp bronchiolitis/

2. respiratory syncytial virus infection/

3. RSV\$.tw.

4. bronchioliti\$.tw.

5. or/1-4

6. exp coughing/

7. wheezing/

8. cough\$.tw.

9. wheez\$.tw.

10. post-viral\$.tw.

11. post-acute\$.tw.

12. co.fs.

13. recurrent disease/

14. or/6-13

15. 5 and 14

16. post-RSV\$.tw.

17. post-bronchiolit\$.tw.

18. 15 or 16 or 17

19. exp antibiotic agent/

20. antibiotic\$.tw.

21. exp macrolide/

22. (macrolide\$ or azithromycin or clarithromycin or erythromycin or roxithromycin or spiramycin).tw.

23. (penicillin\$ or amoxicillin or amoxycillin or ampicillin or benzylpenicillin or cloxacillin or dicloxacillin or flucloxacillin or piperacillin or ticarcillin or sulbactam).tw.

24. (cephalosporin\$ or cephalexin or cephaclor or cefaclor or cefepime or cefotaxime or cephamycin\$ or cefotetan or cefoxitin or cefmetazole or cefpirome or cefpodoxime or ceftazidime or ceftriaxone or cephamandole or cephazolin).tw.

25. (fluoroquinolone\$ or ciprofloxacin or enoxacin or norfloxacin or ofloxacin or pefloxacin or fleroxacin or levofloxacin or moxifloxacin).tw.

26. (tetracycline\$ or doxycycline or methacycline or minocycline).tw.

27. (amikacin or gentamicin or neomycin or netilmicin).tw.

28. (clindamycin or lincomycin).tw.

29. (chloramphenicol or amantadine or cotrimoxazole or trimethoprim).tw.

30. or/19-29

Antibiotics for persistent cough or wheeze following acute bronchiolitis in children (Review) 
31.18 and 30

32. child/

33. exp pediatrics/

34. infant/

35. adolescent/

36. (paediatric $\$$ or paediatric $\$$ or child\$ or adolescen $\$$ or infant $\$$ or young $\$$ or preschool\$ or pre-school\$ or newborn $\$$ or new-born\$ or neonat\$ or neo-nat\$).tw.

37. or/32-36

38. 31 and 37

39. Randomized Controlled Trial/

40. randomisation/

41. Controlled Study/

42. Clinical Trial/

43. controlled clinical trial/

44. Double Blind Procedure/

45. Single Blind Procedure/

46. Crossover Procedure/

47. or/39-46

48. (clinica\$ adj3 trial\$).mp.

49. ((singl\$ or doubl\$ or trebl\$ or tripl\$) adj3 (mask\$ or blind\$ or method\$)).mp.

50. exp Placebo/

51. placebo\$.mp.

52. random\$.mp.

53. ((control\$ or prospectiv\$) adj3 (trial\$ or method\$ or stud\$)).mp.

54. (crossover\$ or cross-over\$).mp.

55. or/48-54

56.47 or 55

57. $\exp$ ANIMAL/

58. Nonhuman/

59. Human/

60.57 or 58

61.60 not 59

62.56 not 61

63. 38 and 62 


\section{Clinicaltrials.gov}

Search terms=bronchiolitis

Study type=interventional studies

Interventions=antibiotics

WHAT'S NEW

\begin{tabular}{lll}
\hline Date & Event & Description \\
\hline 26 August 2016 & $\begin{array}{l}\text { New citation required but conclusions } \\
\text { have not changed }\end{array}$ & $\begin{array}{l}\text { One new study included } \\
\text { Review author group changed and review updated to current } \\
\text { Cochrane format }\end{array}$ \\
& Background/methods/results/discussion updated \\
& $\begin{array}{l}\text { Primary and secondary outcomes updated to reflect more rele- } \\
\text { vant outcomes }\end{array}$ \\
& 'Summary of findings' table added \\
& New 'Risk of bias' tool used \\
\hline 26 August 2016 & New search has been performed & New literature search run \\
\hline
\end{tabular}

\section{CONTRIBUTIONS OF AUTHORS}

GBM and ABC wrote the protocol. PSM reviewed the protocol. For the 2012 review, GBM and ABC, and for the 2016 search, GBM and EJP, independently reviewed the search, double-entered data, and wrote the manuscript. ABC amended the manuscript, and PSM reviewed the manuscript.

\section{DECLARATIONS OF INTEREST}

Three review authors (GBM, PSM, and ABC) were authors of the McCallum 2015 paper. Review author EJP, who was not involved in the McCallum 2015 trial, extracted data for this review.

\section{SOURCES OF SUPPORT}

\section{Internal sources}

- The authors declare that no such funding was received for this systematic review, Other.

\section{External sources}

- National Health Medical Research Council, Australia.

Salary support for GBM, early career fellowship, grant number 1111705

- National Health Medical Research Council, Australia.

Salary support for ABC, practitioner fellowship, grant number 1058213

- NHMRC Centre of Research Excellence Grant, Australia.

CRE in respiratory health in Aboriginal and Torres Strait Islander children, grant number 1040830

\section{DIFFERENCES BETWEEN PROTOCOLANDREVIEW}

The previous review used a hierarchy of assessment and was difficult to read. For this review update, instead of using a hierarchy of assessment, we modified primary and secondary outcomes for the purpose of providing clarity. We included an additional primary outcome for exacerbation rate and moved adverse events and bacterial resistance to secondary outcomes. We updated the methods to 
reflect current reporting, which included adding a risk of bias tool and an SOF table. For this review update, we planned but did not perform three sensitivity analyses, which we will likely perform in the future; we updated the inclusion criteria to make them more applicable to the primary question. Using a random-effects model (when we detected heterogeneity), we performed our analysis by treatment received.

\section{IN DEX TERMS}

\section{Medical Subject Headings (MeSH)}

Acute Disease; Anti-Bacterial Agents [ ${ }^{\star}$ therapeutic use]; Bronchiolitis [ ${ }^{*}$ complications] [virology]; Clarithromycin [ ${ }^{\star}$ therapeutic use]; Cough [ ${ }^{\star}$ drug therapy] [etiology]; Randomized Controlled Trials as Topic; Respiratory Sounds [ ${ }^{\star}$ drug effects] [etiology]; Respiratory Syncytial Virus Infections [complications] [*drug therapy]

\section{MeSH check words}

Humans; Infant 